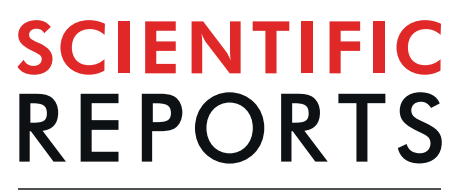

natureresearch

Check for updates

\title{
Paediatric computed tomography and subsequent risk of leukaemia, intracranial malignancy and lymphoma: a nationwide population-based cohort study
}

\author{
I-Gung Li ${ }^{1}$, Yao-Hsu Yang $\mathbb{D}^{2,3,4}$, Yiu-Tai Li ${ }^{5}$ \& Yuan-Hsiung Tsai ${ }^{1,4} \bowtie$
}

Red bone marrow and brain tissue are highly radiosensitive in children. We investigate the relationship between childhood computed tomography (CT) exposure and leukaemia, intracranial malignancy and lymphoma. All participants in the study were aged less than 16 years. A total of 1,479 patients in the leukaemia group, 976 patients in the intracranial malignancy group and 301 patients in the lymphoma group were extracted from the Catastrophic Illness Certificate Database in Taiwan as the disease group. In total, 126,677 subjects were extracted from the Longitudinal Health Insurance Database 2010 of the Taiwan National Health Insurance Research Database as the non-disease group. The odds ratios (ORs) and $95 \%$ confidence intervals (Cls) for childhood CT exposure and times of childhood CT were estimated. Childhood CT exposure was correlated to the intracranial malignancy group in both oneyear $(\mathrm{OR}=1.95,95 \% \mathrm{Cl} 1.40-2.71, p<0.001)$ and two-year $(\mathrm{OR}=1.56,95 \% \mathrm{Cl} 1.04-2.33, p=0.031)$ exclusion periods. The time of childhood CT was also correlated to intracranial malignancy in both oneyear $(\mathrm{OR}=1.69,95 \% \mathrm{Cl} 1.34-2.13, p<0.001)$ and two-year $(\mathrm{OR}=1.55,95 \% \mathrm{Cl} 1.17-2.04, p=0.002)$ exclusion periods. The results indicated that childhood $\mathrm{CT}$ exposure was correlated with an increased risk of future intracranial malignancy.

Computed tomography (CT) is widely used in modern hospitals and provides accurate, timely information. A previous study estimated that 29,000 cases of cancer and 14,500 deaths in the general population annually in the U.S. may be induced by CT exposure ${ }^{1}$. An official report from Australia noted that an irradiation dose of over $20 \mathrm{mSv}$ for the general population was associated with a greater than one in 1000 risk of developing fatal cancers, non-fatal cancers and serious hereditary diseases ${ }^{2,3}$. Recently, many studies have found that ionizing radiation exposure in children may cause serious complications, including malignancy ${ }^{4-7}$. Several studies demonstrated that red bone marrow and brain tissue were highly radiosensitive, especially during childhood ${ }^{8-10}$. A recent report pointed out that the increase in the incidence of all cancers in CT-exposed individuals aged 0-19 years was 9.38 per 100,000 person years in Australia ${ }^{5}$. A study from the United Kingdom reported that the relative risk (RR) for individuals aged 0-22 years who received bone marrow radiation doses greater than $30 \mathrm{mGy}$ was 3.18 , and the risk for patients who received brain radiation doses greater than $50 \mathrm{mGy}$ was $2.82^{4}$.

Leukaemia, intracranial malignancy and lymphoma are the most common malignancies in children in Taiwan ${ }^{11}$. Many studies have pointed out a relationship between leukaemia, intracranial malignancy and ionizing radiation exposure $1,9,12-16$. Therefore, we aim to investigate the relationships between childhood CT exposure and these three major malignancies using cohort data from the Taiwan National Health Insurance research database (NHIRD).

\footnotetext{
${ }^{1}$ Department of Diagnostic Radiology, Chang Gung Memorial Hospital, Chiayi County, Taiwan. ${ }^{2}$ Health Information and Epidemiology Laboratory, Chang Gung Memorial Hospital, Chiayi County, Taiwan. ${ }^{3}$ Department of Traditional Chinese Medicine, Chang Gung Memorial Hospital, Chiayi County, Taiwan. ${ }^{4}$ School of Traditional Chinese Medicine, College of Medicine, Chang Gung University, Taoyuan, Taiwan. ${ }^{5}$ Department of Obstetrics and Gynecology, Kuo General Hospital, Tainan, Taiwan. ${ }^{\bowtie}$-mail: russell.tsai@gmail.com
} 


\begin{tabular}{|c|c|c|c|c|c|c|c|c|c|c|c|c|c|c|c|}
\hline \multirow[b]{3}{*}{ Variables } & \multirow{2}{*}{\multicolumn{2}{|c|}{\begin{tabular}{|l|} 
Leukaemia \\
$(n=1423)$
\end{tabular}}} & \multirow{2}{*}{\multicolumn{2}{|c|}{$\begin{array}{l}\text { Control } \\
(n=14230)\end{array}$}} & \multirow{3}{*}{$\begin{array}{l}p \\
\text { value }\end{array}$} & \multirow{2}{*}{\multicolumn{2}{|c|}{\begin{tabular}{|l|}
$\begin{array}{l}\text { Intracranial } \\
\text { malignancy }\end{array}$ \\
$(n=838)$ \\
\end{tabular}}} & \multirow{2}{*}{\multicolumn{2}{|c|}{\begin{tabular}{|l|} 
Control \\
$(n=8380)$
\end{tabular}}} & \multirow[b]{3}{*}{$p$ value } & \multirow{2}{*}{\multicolumn{2}{|c|}{\begin{tabular}{|l} 
Lymphoma \\
$(n=272)$
\end{tabular}}} & \multirow{2}{*}{\multicolumn{2}{|c|}{\begin{tabular}{|l|} 
Control \\
$(n=2720)$
\end{tabular}}} & \multirow{3}{*}{$\begin{array}{l}p \\
\text { value }\end{array}$} \\
\hline & & & & & & & & & & & & & & & \\
\hline & $n$ & $\%$ & $n$ & $\%$ & & $n$ & $\%$ & $n$ & $\%$ & & $n$ & $\%$ & $n$ & $\%$ & \\
\hline Gender & & & & & 1.000 & & & & & 1.000 & & & & & 1.000 \\
\hline Male & 791 & 55.6 & 7910 & 55.6 & & 479 & 57.2 & 4790 & 57.3 & & 169 & 62.1 & 1690 & 62.1 & \\
\hline Female & 632 & 44.4 & 6320 & 44.4 & & 359 & 42.8 & 3590 & 42.7 & & 103 & 37.9 & 1030 & 37.9 & \\
\hline Age on index day* & & & & & 1.000 & & & & & 1.000 & & & & & 1.000 \\
\hline$\leq 6$ & 1103 & 77.5 & 11030 & 77.5 & & 542 & 64.7 & 5420 & 64.7 & & 115 & 42.3 & 1150 & 42.3 & \\
\hline$>6$ & 320 & 22.5 & 3200 & 22.5 & & 296 & 35.3 & 2960 & 35.3 & & 157 & 57.7 & 1570 & 57.7 & \\
\hline Urbanization level & & & & & 1.000 & & & & & 1.000 & & & & & 1.000 \\
\hline 1 (city) & 400 & 28.1 & 4000 & 28.1 & & 217 & 25.9 & 2170 & 25.9 & & 76 & 27.9 & 760 & 27.9 & \\
\hline 2 & 701 & 49.3 & 7010 & 49.3 & & 378 & 45.1 & 3780 & 45.1 & & 120 & 44.1 & 1200 & 44.1 & \\
\hline 3 & 207 & 14.6 & 2070 & 14.6 & & 147 & 17.5 & 1470 & 17.5 & & 40 & 14.7 & 400 & 14.7 & \\
\hline 4 (villages) & 115 & 8.1 & 1150 & 8.1 & & 96 & 11.5 & 960 & 11.5 & & 36 & 13.2 & 360 & 13.2 & \\
\hline $\begin{array}{l}\text { CT: one-year } \\
\text { exclusion period }\end{array}$ & & & & & 0.853 & & & & & $<0.001$ & & & & & 0.247 \\
\hline Yes & 34 & 2.4 & 329 & 2.3 & & 45 & 5.4 & 240 & 2.9 & & 13 & 4.8 & 93 & 3.4 & \\
\hline No & 1389 & 97.6 & 13901 & 97.7 & & 793 & 94.6 & 8140 & 97.1 & & 259 & 95.2 & 2627 & 96.6 & \\
\hline $\begin{array}{l}\text { CT: two-year } \\
\text { exclusion period }\end{array}$ & & & & & 0.494 & & & & & 0.031 & & & & & 0.860 \\
\hline Yes & 21 & 1.5 & 245 & 1.7 & & 29 & 3.5 & 190 & 2.3 & & 7 & 2.6 & 75 & 2.8 & \\
\hline No & 1402 & 98.5 & 13985 & 98.3 & & 809 & \begin{tabular}{|l|}
96.5 \\
\end{tabular} & 8190 & 97.7 & & 265 & 97.4 & 2645 & 97.2 & \\
\hline
\end{tabular}

Table 1. Characteristics of the Study Patients with Leukaemia, Intracranial Malignancy and Lymphoma from the CICD and of the Comparison Controls from the LHID 2010. Abbreviations: LHID = Longitudinal Health Insurance Database; $\mathrm{CICD}=$ Catastrophic Illness Certificate Database; CT = computed tomography. *The index date was the disease diagnosis date in the disease group and the corresponding date in the non-diseased group.

\section{Results}

Data from 126,677 subjects were extracted from the Longitudinal Health Insurance Database (LHID) 2010, and 2,202 subjects were excluded due to either cancer or any nuclear medicine procedure history. Therefore, a total of 124,475 subjects were in the non-disease group and were matched to each disease group as controls. In the leukaemia group, 1,583 patients with leukaemia were recruited from the Catastrophic Illness Certificate Database (CICD). Among them, 57 patients were excluded due to either other cancer or any nuclear medicine procedure one year before the diagnosis of leukaemia. A total of 1,423 leukaemia patients in the final leukaemia group were matched to 14,230 subjects from the non-disease group for a ratio of one leukaemia case to ten controls matched by gender, year of birth and urbanization level. In the intracranial malignancy group, 897 patients with intracranial malignancy were recruited from the CICD. Among them, 37 patients were excluded due to either other cancer or any nuclear medicine procedure one year before the diagnosis of intracranial malignancy. A total of 838 patients in the final intracranial malignancy group were matched to 8,380 subjects from the non-disease group for a ratio of one intracranial malignancy case to ten controls matched by gender, year of birth and urbanization level. In the lymphoma group, 301 patients with lymphoma were recruited from the CICD. Among them, 21 patients were excluded due to either other cancer or any nuclear medicine procedure one year before the diagnosis of lymphoma. A total of 272 patients were included in the final lymphoma group and were matched to 2,720 subjects from the non-disease group for a ratio of one lymphoma case to ten controls matched by gender, year of birth and urbanization level.

The characteristics of the study subjects in this article are shown in Table 1. The adjusted ORs of childhood CT exposure and times of childhood CT in one- and two-year exclusion periods are listed in Table 2. The adjusted ORs of childhood CT exposure were significantly increased in the cases of the intracranial malignancy group compared to the controls in both one-year $(\mathrm{OR}=1.95,95 \% \mathrm{CI} 1.40-2.71, p<0.001)$ and two-year exclusion periods $(\mathrm{OR}=1.56,95 \% \mathrm{CI} 1.04-2.33, p=0.031)$. The adjusted ORs of times of childhood CT were also significantly increased in both one-year $(\mathrm{OR}=1.69,95 \% \mathrm{CI} 1.34-2.13, p<0.001)$ and two-year exclusion periods $(\mathrm{OR}=1.55$, $95 \%$ CI 1.17-2.04, $p=0.002)$ compared to controls. The adjusted ORs of greater or equal to two times of childhood CT were significantly increased in both one-year exclusion period (OR $=2.80,95 \% \mathrm{CI} 1.21-6.48, p=0.001)$ and two-year exclusion periods $(\mathrm{OR}=2.84,95 \% \mathrm{CI} 1.05-7.69, p=0.040)$ compared to controls. The adjusted ORs showed no significant difference for childhood CT exposure and times of childhood CT in both the leukaemia and the lymphoma group. Considering that the age at first CT exposure may affect the occurrence of childhood leukaemia, intracranial malignancy and lymphoma, an analysis was performed, and the results are listed in Table 3. The results showed no significant difference in age at first CT exposure between those younger and equal to six years old and those older than six years old in both one- and two-year exclusion periods in the three groups.

\section{Discussion}

This study is a nationwide, population-based, retrospective, case-control study. In this study, for intracranial malignancy patients under 16 years of age, childhood CT exposure resulted in significantly elevated ORs compared to controls in both the one- and two-year exclusion periods. The times of CT also significantly correlated with the risk of intracranial malignancy in both one- and two-year exclusion periods. The results indicated that 


\begin{tabular}{|c|c|c|c|c|c|c|}
\hline \multirow[b]{2}{*}{ Variables } & \multicolumn{2}{|l|}{ Leukaemia } & \multicolumn{2}{|c|}{ Intracranial malignancy } & \multicolumn{2}{|l|}{ Lymphoma } \\
\hline & Adjusted OR* & $p$ value & Adjusted OR* & $p$ value & Adjusted OR* & $p$ value \\
\hline \multicolumn{7}{|c|}{ One-year exclusion period } \\
\hline \multicolumn{7}{|c|}{ CT } \\
\hline No & 1.00 & & 1.00 & & 1.00 & \\
\hline Yes & $1.04(0.72-1.48)$ & 0.851 & $1.95(1.40-2.71)$ & $<0.001$ & $1.42(0.78-2.59)$ & 0.246 \\
\hline $\begin{array}{l}\text { Times of } \\
\text { CT }\end{array}$ & $1.14(0.89-1.47)$ & 0.293 & $1.69(1.34-2.13)$ & $<0.001$ & $1.33(0.82-2.15)$ & 0.243 \\
\hline \multicolumn{7}{|c|}{ Times of CT/cases } \\
\hline 0 & 1.00 & & 1.00 & & 1.00 & \\
\hline 1 & $0.96(0.65-1.43)$ & 0.853 & $1.84(1.29-2.63)$ & 0.001 & $1.35(0.71-2.57)$ & 0.364 \\
\hline$\geq 2$ & $1.59(0.67-3.76)$ & 0.295 & $2.80(1.21-6.48)$ & 0.016 & $2.03(0.44-9.33)$ & 0.362 \\
\hline \multicolumn{7}{|c|}{ Two-year exclusion period } \\
\hline \multicolumn{7}{|c|}{ CT } \\
\hline No & 1.00 & & 1.00 & & 1.00 & \\
\hline Yes & $0.85(0.54-1.34)$ & 0.492 & $1.56(1.04-2.33)$ & 0.031 & $0.93(0.42-2.05)$ & 0.859 \\
\hline $\begin{array}{l}\text { Times of } \\
\text { CT }\end{array}$ & $1.07(0.78-1.45)$ & 0.686 & $1.55(1.17-2.04)$ & 0.002 & $0.96(0.50-1.86)$ & 0.907 \\
\hline \multicolumn{7}{|c|}{ Times of CT/cases } \\
\hline 0 & 1.00 & & 1.00 & & 1.00 & \\
\hline 1 & $0.74(0.44-1.23)$ & 0.246 & $1.43(0.92-2.21)$ & 0.113 & $0.88(0.38-2.05)$ & 0.767 \\
\hline$\geq 2$ & $1.72(0.66-4.45)$ & 0.266 & $2.84(1.05-7.69)$ & 0.040 & $1.43(0.18-11.67)$ & 0.740 \\
\hline
\end{tabular}

Table 2. The Adjusted ORs for CT Exposure and Its Frequency for Leukaemia, Intracranial Malignancy and Lymphoma with One-year or Two-year Exclusion Period. Abbreviations: OR = odds ratio; CT = computed tomography. *The model was adjusted by year of birth, gender and urbanization level.

\begin{tabular}{|c|c|c|c|c|c|c|c|c|c|}
\hline \multirow[b]{2}{*}{ Variables } & \multicolumn{3}{|c|}{ Leukaemia } & \multicolumn{3}{|c|}{ Intracranial malignancy } & \multicolumn{3}{|c|}{ Lymphoma } \\
\hline & $n$ & Adjusted OR* & $p$ value & $n$ & Adjusted OR* & $p$ value & $n$ & Adjusted OR* & $p$ value \\
\hline \multicolumn{10}{|c|}{ One-year exclusion period } \\
\hline \multicolumn{10}{|c|}{\begin{tabular}{l|l|}
$\begin{array}{l}\text { Age at first CT } \\
\text { exposure }\end{array}$ & \\
\end{tabular}} \\
\hline$\leq 6$-year-old & 30 & 1 & & 37 & 1 & & 10 & 1 & \\
\hline$>6$-year-old & 4 & $0.91(0.31-2.72)$ & 0.868 & 8 & $1.22(0.53-2.84)$ & 0.638 & 3 & $1.17(0.29-4.67)$ & 0.826 \\
\hline \multicolumn{10}{|c|}{ Two-year exclusion period } \\
\hline \multicolumn{10}{|l|}{$\begin{array}{l}\text { Age at first CT } \\
\text { exposure }\end{array}$} \\
\hline$\leq 6$-year-old & 20 & 1 & & 24 & 1 & & 6 & 1 & \\
\hline$>6$-year-old & 1 & $0.40(0.05-3.13)$ & 0.386 & 5 & $1.59(0.55-4.60)$ & 0.391 & 1 & $0.73(0.08-6.53)$ & 0.776 \\
\hline
\end{tabular}

Table 3. The Adjusted ORs for the Age at First CT Exposure for Leukaemia, Intracranial Malignancy, and Lymphoma in One-year or Two-year Exclusion Period. Abbreviations: OR= odds ratio; CT = computed tomography. *The model was adjusted by year of birth, gender and urbanization level.

childhood CT exposure was correlated with increasing risk of a future intracranial malignancy in Taiwan; however, the same trend was not found in the leukaemia or lymphoma group. A current theory postulates that ionizing radiation energy overpowers the binding energy of atom-orbiting electrons and knocks electrons out of their orbit, thereby creating radicals. Biological effects cause double-strand DNA breaks or damage, and cancer may be induced by occasional point mutations, chromosome translocations or gene fusion ${ }^{16}$.

An investigation of radiation-induced cancer in atomic bomb survivors found that leukaemia developed in the majority of children; most types of leukaemia, other than chronic lymphocytic leukaemia, may be induced by ionizing radiation with a minimum latency of approximately two years ${ }^{17}$. Some reports also mentioned that childhood leukaemia was diagnosed 3 years after the first exposure; however, the peak diagnosis time was 6-8 years $^{18-20}$. Although leukaemia is strongly associated with childhood radiation exposure in atomic bomb survivors, a similar result was not established in this study. Ionizing radiation has been found to induce some types of nervous system tumours and shows marked differences depending on age at exposure. The United Nations Scientific Committee on the Effects of Atomic Radiation (UNSCEAR) 2006 Report demonstrated that malignant tumours of the central nervous system were reported mostly after high-dose radiotherapy and after exposure in childhood. Gliomas are the tumours with the highest risk in those younger than five years old exposed to radiation; this risk dramatically decreases in those older than 20 years old, possibly indicating that susceptibility markedly decreases as brain development nears completion ${ }^{21}$. 


\begin{tabular}{|c|c|c|c|c|c|c|c|c|}
\hline & $\begin{array}{l}\text { Exclusion } \\
\text { period } \\
\text { (Year) }\end{array}$ & Database & Sample size & Age & $\begin{array}{l}\text { Follow up } \\
\text { period }\end{array}$ & Leukaemia result & $\begin{array}{l}\text { Brain tumour } \\
\text { result }\end{array}$ & $\begin{array}{l}\text { Lymphoma } \\
\text { result }\end{array}$ \\
\hline $\begin{array}{l}\text { Pearce } e t \\
\text { al. }(2012 \\
\text { retrospective } \\
\text { cohort study) }\end{array}$ & $\begin{array}{l}2 \text { for } \\
\text { Leukaemia; } \\
5 \text { for brain } \\
\text { tumour }\end{array}$ & $\begin{array}{l}\text { NHS, United } \\
\text { Kingdom }\end{array}$ & \begin{tabular}{|l|}
178,604 with \\
Leukaemia; \\
176587 \\
with brain \\
tumour
\end{tabular} & $0-22$ & 1985-2008 & $\begin{array}{l}\text { ERR per } \mathrm{mGy} \text { : } \\
0.036(95 \% \mathrm{CI} \\
0.005-0120 \\
p=0.0097)\end{array}$ & \begin{tabular}{|l|} 
ERR per \\
mGy: 0.023 \\
(95\% CI \\
$0.010-0.049 ;$ \\
$p<0.0001)$
\end{tabular} & NA \\
\hline $\begin{array}{l}\text { Mathews } \\
\text { et al. }(2013 \\
\text { retrospective } \\
\text { cohort study) }\end{array}$ & 1 & AIHW, Australia & $10,939,680$ & $0-20$ & $1985-2007$ & $\begin{array}{l}\text { Leukaemias and } \\
\text { myelodysplasias } \\
\text { IRR: } 1.23(95 \% \mathrm{CI} \text { : } \\
1.08-2.41) \\
\text { ERR per mGy: } \\
0.039(95 \% \mathrm{CI} \\
-0.014-0.070)\end{array}$ & $\begin{array}{l}\text { All CT scan: } \\
\text { IRR: } 2.13 \\
\text { (95\% CI: } \\
\text { 1.88-2.41); } \\
\text { Only Brain } \\
\text { CT: IRR: } 2.44 \\
\text { (95\% CI: } \\
\text { 2.12-2.81) } \\
\text { ERR per } \\
\text { mGy: } 0.029 \\
\text { (95\% CI: } \\
-0.023- \\
0.037)\end{array}$ & $\begin{array}{l}\text { Hodgkin's } \\
\text { lymphoma } \\
\text { IRR: } 1.15 \\
\text { (CI:1.01- } \\
1.32) ; \\
\text { Other } \\
\text { lymphoma } \\
\text { IRR: } 1.01 \text { (CI: } \\
0.82-1.23 \text { ) }\end{array}$ \\
\hline $\begin{array}{l}\text { Huang } e t \\
\text { al. (2014 } \\
\text { retrospective } \\
\text { cohort study) }\end{array}$ & 2 & NHIRD, Taiwan & 122,086 & $0-18$ & 1998-2008 & $\begin{array}{l}\text { HR: } 1.90 \text { (95\% CI: } \\
0.82-4.40)\end{array}$ & $\begin{array}{l}\text { All brain } \\
\text { tumour HR: } \\
2.56 \text { (95\% CI: } \\
1.44-4.54 ; \\
p<0.01) ; \\
\text { Malignancy } \\
\text { HR: } 1.84 \\
(95 \% \text { CI: } \\
0.64-5.29)\end{array}$ & NA \\
\hline \multirow[t]{2}{*}{$\begin{array}{l}\text { Journy et } \\
\text { al. (2015 } \\
\text { retrospective } \\
\text { cohort study) }\end{array}$} & 1 & $\begin{array}{l}23 \text { department, } \\
\text { France }\end{array}$ & 67,274 & $0-10$ & $2000-2010$ & $\begin{array}{l}\text { ERR per mGy: } \\
0.014(95 \% \text { CI: } \\
-0.037-0.065)\end{array}$ & $\begin{array}{l}\text { ERR per } \\
\text { mGy: } 0.017 \\
\text { (95\% CI: } \\
-0.010- \\
0.044)\end{array}$ & $\begin{array}{l}\text { ERR: }-0.002 \\
\text { (95\% CI: } \\
-0.050- \\
0.046)\end{array}$ \\
\hline & 2 & & & & & $\begin{array}{l}\text { ERR per mGy: } \\
0.047(95 \% \text { CI: } \\
-0.065-0.159)\end{array}$ & \begin{tabular}{|l|} 
ERR per \\
mGy: 0.012 \\
(95\% CI: \\
$-0.013-$ \\
$0.037)$
\end{tabular} & $\begin{array}{l}\text { ERR: } 0.008 \\
\text { (95\% CI: } \\
-0.057- \\
0.073)\end{array}$ \\
\hline $\begin{array}{l}\text { Krille et } \\
\text { al. }(2015 \\
\text { retrospective } \\
\text { cohort study) }\end{array}$ & 2 & GCCR, Germany & 44,584 & $0-15$ & $1980-2010$ & $\begin{array}{l}\text { SIR: } 1.72 \text { (95\% CI: } \\
0.89-3.01)\end{array}$ & $\begin{array}{l}\text { SIR: } 1.35 \\
\text { (95\% CI: } \\
0.54-2.78)\end{array}$ & $\begin{array}{l}\text { SIR: } 3.26 \\
\text { (95\% CI: } \\
1.63-5.83 \text { ) }\end{array}$ \\
\hline \multirow[t]{2}{*}{$\begin{array}{l}\text { Li et al. }(2020 \\
\text { retrospective } \\
\text { cohort study) }\end{array}$} & 1 & NHIRD, Taiwan & 126,677 & $0-16$ & $1998-2013$ & $\begin{array}{l}\text { OR: } 1.04(95 \% \text { CI: } \\
0.72-1.48)\end{array}$ & \begin{tabular}{|l|} 
OR: $1.95(95 \%$ \\
CI:1.40-2.71, \\
$\mathrm{P}<0.001)$
\end{tabular} & $\begin{array}{l}\text { OR: } 1.42 \\
\text { (95\% CI: } \\
0.78-2.59)\end{array}$ \\
\hline & 2 & & & & & $\begin{array}{l}\text { OR: } 0.85 \text { (95\% CI: } \\
0.54-1.34)\end{array}$ & $\begin{array}{l}\text { OR: } 1.56(95 \% \\
\text { CI: } 1.04-2.33 \\
\mathrm{P}=0.031)\end{array}$ & $\begin{array}{l}\text { OR: } 0.93 \\
\text { (95\% CI: } \\
0.42-2.05 \text { ) }\end{array}$ \\
\hline
\end{tabular}

Table 4. Comparison of Epidemiology and Risk Evaluations for Leukaemia, Brain Tumour and Lymphoma with our Study. Abbreviations: NHS = National Health Service; AIHW = Australian Institute of Health and Welfare; NHIRD = National Institutes of Health research database; GCCR $=$ German Childhood Cancer Registry; $\mathrm{RR}=$ risk ratio; $\mathrm{HR}=$ hazard ratio; $\mathrm{ERR}=$ excess relative risks; $\mathrm{OR}=$ odds ratio; $\mathrm{SIR}=$ standardized incidence ratios; $\mathrm{NA}=$ not available; $95 \% \mathrm{CI}=95 \%$ confidence interval.

Previous studies about the correlations between childhood CT exposure and the risk of lymphoma, leukemia and brain tumors are summarized in Table 4. Some causal links between childhood CT exposure and intracranial tumour incidence were identified with similar results in previous studies. According to an investigation of the cancer incidence rate of 10.9 million people in Australia, the overall incidence rate ratio (IRR) for brain cancers (ICD-10: C69-72) based on a one-year exclusion period was 2.13 (CI 1.88-2.41) $)^{5}$. A UK study found that the excess relative risk (ERR) per mGy for brain tumours in a 5-year exclusion period was 0.023 (95\% CI 0.010-0.049; $p<0.0001$ ). The relative risk of brain tumour for individuals who received a cumulative dose of 50-74 mGy (mean dose 60.42 mGy) was up to 2.82 (95 CI: 1.33-6.03) compared with individuals who received a dose of less than $5 \mathrm{mGy}$. For individuals who received a cumulative dose of $50 \mathrm{mGy}$ or more (mean dose 104.16 $\mathrm{mGy}$ ), the relative risk was 3.32 (95 CI: $1.84-6.42)^{4}$. A German study also reported a standardized incidence ratio $(\mathrm{SIR}=$ cancer observed/expected $)$ of 1.35 (95\% CI 0.54-2.78) for CNS tumours ${ }^{22}$. Another study including data from 21 French university hospitals based on a one-year exclusion period reported an ERR per mGy of 0.017 (95\% CI 0.010-0.044) for CNS cancer. After adjusting for known predisposing factors, the authors observed no significant increased risk related to CT exposure ${ }^{23}$. A Taiwanese study also reported that the hazard ratio (HR) for all brain tumours was higher, at 2.56 (95 CI 1.44-4.54, $p<0.01$ ), in the exposed cohort than in the unexposed cohort, but the overall risk of malignancy and benign brain tumour was not significantly different between the two cohorts. The frequency of CT scans showed a strong correlation with all brain tumours (increase in HR from 2.32 to $10.4, p=0.0001$ ) compared with the unexposed cohort $^{24}$, similar to the finding in our study. 
However, the evidence linking childhood lymphoma and exposure to ionizing radiation is weak. According to the UNSCEAR 2013 report, Hodgkin lymphomas were barely associated with ionizing radiation ${ }^{17}$. For non-Hodgkin lymphomas, the Life Span Study reported no association with ionizing radiation in males, but there was an association in females ${ }^{25}$. Overall, there is no current evidence for a significant dose-response relationship for either Hodgkin or non-Hodgkin lymphomas, similar to the finding in our study. Regarding the age at exposure, a previous report on atomic bomb exposure survivors ${ }^{26}$ noted that the younger population may have higher risk for malignancy. However, we did not find the same trend in our study. A small sample size and uneven sample size distribution may cause this result.

The reason for using an exclusion period in this study, as well as in the previous literature, was to exclude the possibility of reverse causation because either precancerous or early-stage symptoms of cancer itself might prompt a CT scan, potentially causing indication bias ${ }^{27}$. The exclusion period before the disease diagnosis is critical, and both one and two years were included in this study. An applicable length of the exclusion period between the exposure to ionizing radiation and the progression of associated cancers is unclear ${ }^{24}$. Some studies demonstrated that leukaemia cases occurred as early as 1-3 years after radiation therapy of cancer ${ }^{28-30}$. A 2014 report from the Centers for Disease Control and Prevention (CDC) suggests that the minimum exclusion period for lymphoproliferative and haematopoietic cancers (including all types of leukaemia and lymphoma) is 0.4 years, and the minimum period for childhood cancers (other than lymphoproliferative and haematopoietic cancers), including brain tumours, is 1 year ${ }^{31}$. Unfortunately, the current data pool with longer exclusion periods is not large enough, and a large-scale study with a longer follow-up period is necessary to confirm this result.

This study had several strengths. A large sample size was obtained with the use of nationwide data, resulting in increased statistical sensitivity and power. The large sample size also minimized the loss to follow-up and allowed the accurate calculation times of CT in all subjects due to the widespread coverage of the NHI database, which included more than $99 \%$ of the population in Taiwan. Each leukaemia, brain malignancy and lymphoma diagnosis was made by a physician and reported with ICD-9-CM codes in the Registry of Catastrophic Illnesses patient database. Misclassification bias was minimized due to the strict censoring of this social welfare database.

This study also had some limitations. First, uniformly estimated organ-absorbed radiation doses to evaluate the dose-response relationship were not achieved because of the lack of information on actual absorbed doses from NHIRD. Consequently, we adopted childhood CT exposure and times of childhood CT exposure as our target variables due to their applicability to real life, and we believed that a large sample size might mediate the large variations in effective radiation doses. The results of our study are in line with previous reports that both the times and radiation dose of CT exposure are related to childhood malignancies ${ }^{4-6,22,24,27}$. Second, basic medical information and risk factors other than CT exposure that might associate with the development of malignancies were not included in the analysis. We did check the comorbidities, including some rare diseases associated with malignancies for each subject, but only few cases were identified and thus were ignored in the analysis. Information regarding other risk factors such as environment and substance exposure were not included in the database. Furthermore, this study did not consider radiation doses from other common medical examinations. In addition to CT, many other iatrogenic ionizing radiation examinations, including conventional X-ray imaging and intervention procedures, are administered in the hospital. The CT ionizing radiation doses are 100 to 500 times higher than those of conventional radiography and are more likely to be linked to an increased risk of cancer ${ }^{32,33}$.

\section{Methods}

Data source. Longitudinal Health Insurance Database (LHID) 2010. LHID 2010 is a subset of data that contains the original claims data of 1 million beneficiaries systemically and randomly sampled from the year 2010 Registry for Beneficiaries of the NHIRD. Everyone in the year 2010 Registry for Beneficiaries of the NHIRD was a beneficiary of the National Health Insurance program during the period of Jan. 1, 2010 to Dec. 31, 2010 and was drawn for random sampling. The latest version of LHID 2010 includes the medical claims of all beneficiaries during the period of 1997 and 2013. This database has been widely applied in epidemiologic and medical research and contains information on prescription use, diagnoses, and cost of hospitalizations ${ }^{34}$. The Taiwan National Health Insurance (NHI) reimbursement system has been in use since March 1995 and contains de-identified medical claims from $98 \%$ of the population of Taiwan ( 23 million people). The detailed medical claims include recorded outpatient visits, hospital admissions, prescriptions, and procedures including times of CT and diagnosis of disease based on International Classification of Diseases, Ninth Revision, Clinical Modification (ICD-9-CM) code. The NHIRD is anonymized and maintained by the National Health Research Institute with confidentiality according to the Personal Electronic Data Protection Law. There were no significant differences in age, gender and average premium rate between individuals in the LHID 2010 and those in the original NHIRD ${ }^{35}$.

The Catastrophic Illness Certificate Database (CICD). Under the NHI program, patients with severe illnesses can apply for catastrophic illness certification, and those who receive care for their illness or related conditions within the certificate's validity period do not pay a co-payment for outpatient or inpatient care. Patients with such illnesses are exempt from medical costs; therefore, the registry database is comprehensive and has excellent validity. The CICD was used to identify cancer patients by ICD-9-CM codes; all cancer patients were histologically or cytologically confirmed before a catastrophic illness certificate was issued during the period of 1997 through 2013.

Population. Figure 1 shows the flowchart for selecting the participants in this study. All recruited individuals in this study were only born after Jan. 1, 1998 to ensure that all of them were under 16 years of age throughout the whole investigational period and complete medical records were available in LHID 2010 and CICD during the period 1997 through 2013. Children who had leukaemia, intracranial malignancy or lymphoma were selected 


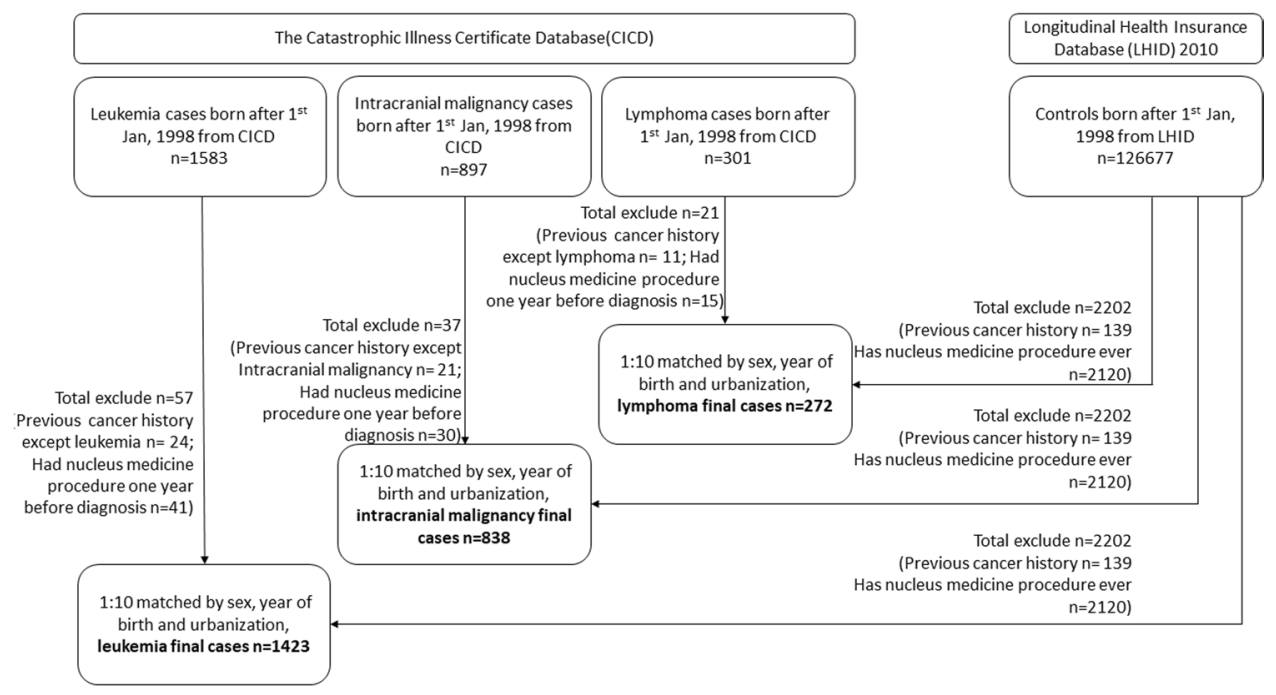

Figure 1. Flowchart for selecting the study participants. Abbreviations: LHID = Longitudinal Health Insurance Database; $\mathrm{CICD}=$ Catastrophic Illness Certificate Database; ICD-9 = International Classification of Disease Ninth Revision.

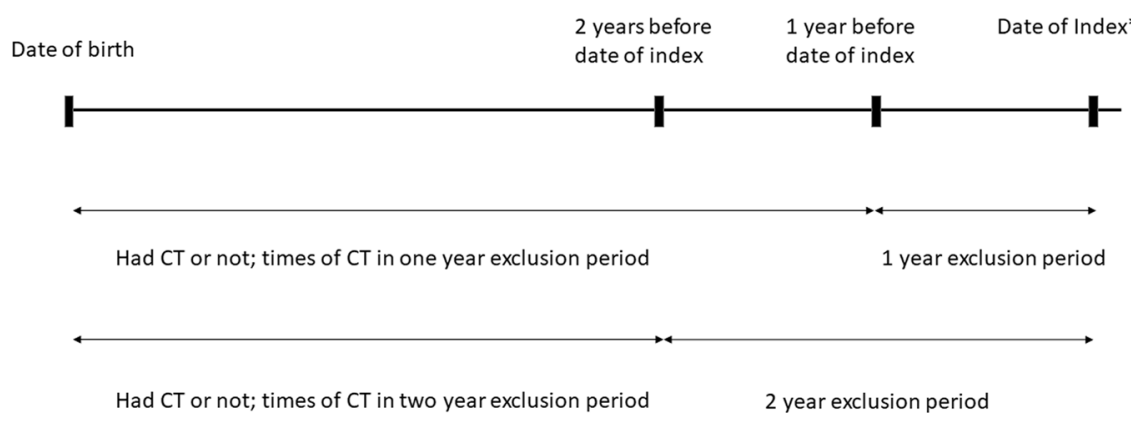

Figure 2. Study design. This figure shows the investigation of childhood CT exposure and times of childhood $\mathrm{CT}$ in case-control matched subjects. The index date was the disease diagnosis date in the disease group and the corresponding date in non-diseased group.

by ICD-9-CM code (leukaemia 204-208.91; intracranial malignancy 191-192.9, 194.3-194.4; lymphoma 200202.28, 2028-202.98) from CICD during the period from 1998 through 2013 as the disease groups. In these three main disease groups, those who had other cancers (ICD-9-CM code 140-208.91; other than 204-208.91 in leukaemia cases; 191-192.9, 194.3-194.4 in intracranial malignancy cases and 200-202.28, 2028-202.98 in lymphoma cases) or nuclear medicine procedures one year before disease diagnosis were excluded. Patients who were unable to be matched to the non-disease group were not enrolled in the final disease group. Individuals were recruited from the LHID 2010 as the non-disease group, and those who had cancer history (ICD-9-CM code 140-208.91) or any nuclear medicine procedure were also excluded.

Exposure and statistical analysis. For each individual in the disease group, ten non-diseased individuals as controls were matched by year of birth, gender and urbanization level. Figure 2 shows the study design in this article. Childhood CT exposure and times of childhood CT one and two years before the index date were recorded. Any CT scan within one and two years before the index date was ignored. This exclusion period was established due to the possibility that CT scan was part of the cancer diagnostic procedure. The index date was the disease diagnosis date in the disease group and the corresponding date in the non-diseased group. The distributions of gender, year of birth, urbanization level and times of CT scans between the cases and the controls were compared. Logistic regression was performed to calculate the odds ratios (ORs) and 95\% confidence intervals (CIs) for childhood CT exposure and times of childhood CT between cases and controls in these three main disease groups with adjustments for birth year, gender and urbanization level. Logistic regression was also performed to calculate the odds ratios (ORs) and 95\% confidence intervals (CIs) of the age of first CT exposure between patients younger and equal to six years old and older than six years old in disease groups. A two-tailed $p$ value of $<0.05$ was considered statistically significant. All statistical analyses in this study were performed using SAS statistical software (version 9.4 for Windows; SAS Institute, Inc., Cary, NC, USA). This study was approved by the Institutional Review Board (IRB) of Chang Gung Medical Foundation (No. 201700967B0), which approved the experiments, including any relevant details that were performed in accordance with relevant guidelines and 
regulations. In our study, de-identification was performed for the whole manuscript, and the IRB approved a waiver of the informed consent form.

\section{Data availability}

All data in this article are available from the National Health Insurance Research Database (NHIRD) published by the Taiwan National Health Insurance (NHI) Bureau. Due to legal restrictions imposed by the government of Taiwan, data cannot be made publicly available. Data requests can be performed by formal proposal to the NHIRD (http://nhird.nhri.org.tw).

Received: 6 October 2019; Accepted: 20 April 2020;

Published online: 08 May 2020

\section{References}

1. Berrington de Gonzalez, A. et al. Projected cancer risks from computed tomographic scans performed in the United States in 2007. Arch. Intern. Med. 169, 2071-2077, https://doi.org/10.1001/archinternmed.2009.440 (2009).

2. Asha, S. et al. Comparison of radiation exposure of trauma patients from diagnostic radiology procedures before and after the introduction of a panscan protocol. Emerg. Med. Australas. 24, 43-51, https://doi.org/10.1111/j.1742-6723.2011.01504.x (2012)

3. Radiation Health Committee. Australian radiation protection and nuclear safety agency. Exposure of humans to ionizing radiation for research purposes, https://www.arpansa.gov.au/sites/g/files/net3086/f/legacy/pubs/rps/rps8.pdf (2005).

4. Pearce, M. S. et al. Radiation exposure from CT scans in childhood and subsequent risk of leukaemia and brain tumours: a retrospective cohort study. Lancet 380, 499-505, https://doi.org/10.1016/S0140-6736(12)60815-0 (2012).

5. Mathews, J. D. et al. Cancer risk in 680,000 people exposed to computed tomography scans in childhood or adolescence: data linkage study of 11 million Australians. BMJ 346, f2360, https://doi.org/10.1136/bmj.f2360 (2013).

6. Miglioretti, D. L. et al. The use of computed tomography in pediatrics and the associated radiation exposure and estimated cancer risk. JAMA Pediatr. 167, 700-707, https://doi.org/10.1001/jamapediatrics.2013.311 (2013).

7. Kritsaneepaiboon, S., Jutiyon, A. \& Krisanachinda, A. Cumulative radiation exposure and estimated lifetime cancer risk in multipleinjury adult patients undergoing repeated or multiple CTs. Eur J Trauma Emerg Surg, https://doi.org/10.1007/s00068-016-0665-6 (2016).

8. Preston, D. L. et al. Cancer incidence in atomic bomb survivors. Part III. Leukemia, lymphoma and multiple myeloma, $1950-1987$. Radiat. Res. 137, S68-97 (1994).

9. Brenner, D., Elliston, C., Hall, E. \& Berdon, W. Estimated risks of radiation-induced fatal cancer from pediatric CT. AJR Am. J. Roentgenol. 176, 289-296, https://doi.org/10.2214/ajr.176.2.1760289 (2001).

10. Chodick, G., Ronckers, C. M., Shalev, V. \& Ron, E. Excess lifetime cancer mortality risk attributable to radiation exposure from computed tomography examinations in children. Isr. Med. Assoc. J. 9, 584-587 (2007).

11. Childhood Cancer Foundation of Republic of China, http://www.ccfroc.org.tw/content_sub.php?id=118\&level1ID =12\&level2ID $=1$ \&level3ID $=1$

12. Rehani, M. M. \& Berry, M. Radiation doses in computed tomography. The increasing doses of radiation need to be controlled. BMJ 320, 593-594 (2000).

13. Parker, L. Computed tomography scanning in children: radiation risks. Pediatr. Hematol. Oncol. 18, 307-308, https://doi. org/10.1080/088800101300312564(2001).

14. Paterson, A., Frush, D. P. \& Donnelly, L. F. Helical CT of the body: are settings adjusted for pediatric patients? AJR Am. J. Roentgenol. 176, 297-301, https://doi.org/10.2214/ajr.176.2.1760297 (2001).

15. Brenner, D. J. \& Elliston, C. D. Estimated radiation risks potentially associated with full-body CT screening. Radiology 232, 735-738, https://doi.org/10.1148/radiol.2323031095 (2004).

16. Brenner, D. J. \& Hall, E. J. Computed tomography-an increasing source of radiation exposure. N. Engl. J. Med. 357, 2277-2284, https://doi.org/10.1056/NEJMra072149 (2007).

17. Radiation, U. N. S. C. o. t. E. o. A. (New York:, 2013).

18. Folley, J. H., Borges, W. \& Yamawaki, T. Incidence of leukemia in survivors of the atomic bomb in Hiroshima and Nagasaki, Japan. Am. J. Med. 13, 311-321 (1952).

19. Richardson, D. et al. Ionizing radiation and leukemia mortality among Japanese Atomic Bomb Survivors, 1950-2000. Radiat. Res. 172, 368-382, https://doi.org/10.1667/RR1801.1 (2009).

20. Kutanzi, K. R., Lumen, A., Koturbash, I. \& Miousse, I. R. Pediatric Exposures to Ionizing Radiation: Carcinogenic Considerations. Int J Environ Res Public Health 13, https://doi.org/10.3390/ijerph13111057 (2016).

21. United Nations. Scientific Committee on the Effects of Atomic Radiation. Effects of ionizing radiation: UNSCEAR 2006 report to the General Assembly, with scientific annexes. (United Nations, 2008).

22. Krille, L. et al. Risk of cancer incidence before the age of 15 years after exposure to ionising radiation from computed tomography: results from a German cohort study. Radiat. Env. Biophys. 54, 1-12, https://doi.org/10.1007/s00411-014-0580-3 (2015).

23. Journy, N., Laurier, D. \& Bernier, M. O. Comment on: Are the studies on cancer risk from CT scans biased by indication? Elements of answer from a large-scale cohort study in France. Br. J. Cancer 112, 1843-1844, https://doi.org/10.1038/bjc.2015.105 (2015).

24. Huang, W. Y. et al. Paediatric head CT scan and subsequent risk of malignancy and benign brain tumour: a nation-wide populationbased cohort study. Br. J. Cancer 110, 2354-2360, https://doi.org/10.1038/bjc.2014.103 (2014).

25. Hsu, W. L. et al. The incidence of leukemia, lymphoma and multiple myeloma among atomic bomb survivors: 1950-2001. Radiat. Res. 179, 361-382, https://doi.org/10.1667/RR2892.1 (2013).

26. UNSCEAR (2013) Report of the United Nations Scientific Committee on the Effects of Atomic Radiation. (2013).

27. Journy, N. et al. Are the studies on cancer risk from CT scans biased by indication? Elements of answer from a large-scale cohort study in France. Br. J. Cancer 112, 185-193, https://doi.org/10.1038/bjc.2014.526 (2015).

28. Boice, J. D. Jr. et al. Radiation dose and leukemia risk in patients treated for cancer of the cervix. J. Natl Cancer Inst. 79, 1295-1311 (1987).

29. Curtis, R. E. et al. Risk of leukemia after chemotherapy and radiation treatment for breast cancer. N. Engl. J. Med. 326, 1745-1751, https://doi.org/10.1056/NEJM199206253262605 (1992).

30. Inskip, P. D. et al. Leukemia, lymphoma, and multiple myeloma after pelvic radiotherapy for benign disease. Radiat. Res. 135, 108-124 (1993).

31. Howard, J. Minimum Latency \& Types or Categories of Cancer, https://www.cdc.gov/wtc/pdfs/policies/ wtchpminlatcancer2014-11-07-508.pdf (2014).

32. National Research Council (U.S.). Committee to Assess Health Risks from Exposure to Low Level of Ionizing Radiation. Health risks from exposure to low levels of ionizing radiation: BEIR VII Phase 2. (National Academies Press, 2006).

33. Preston, D. L. et al. Solid cancer incidence in atomic bomb survivors: 1958-1998. Radiat. Res. 168, 1-64, https://doi.org/10.1667/ RR0763.1 (2007). 
34. Lin, C. M. et al. $131 \mathrm{I}$ treatment for thyroid cancer and risk of developing primary hyperparathyroidism: a cohort study. Eur. J. Nucl. Med. Mol. Imaging 41, 253-259, https://doi.org/10.1007/s00259-013-2541-5 (2014).

35. Hsieh, H. C., Hsu, J. C. \& Lu, C. Y. 10-year trends in statin utilization in Taiwan: a retrospective study using Taiwan's National Health Insurance Research Database. BMJ Open. 7, e014150, https://doi.org/10.1136/bmjopen-2016-014150 (2017).

\section{Acknowledgements}

We would like to thank the Health Information and Epidemiology Laboratory of Chang Gung Memorial Hospital, Chia-Yi Branch, for the comments and assistance in data analysis.

\section{Author contributions}

Yuan-Hsiung Tsai contributed to study conception, design and general supervision of the research group. I-Gung Li was involved in data interpretation and was a major contributor in writing the manuscript. Yao-Hsu Yang contributed to comments and assistance in data analysis. Yiu-Tai Li contributed to critical revision of the manuscript. All authors read and approved the final manuscript.

\section{Competing interests}

The authors declare no competing interests.

\section{Additional information}

Correspondence and requests for materials should be addressed to Y.-H.T.

Reprints and permissions information is available at www.nature.com/reprints.

Publisher's note Springer Nature remains neutral with regard to jurisdictional claims in published maps and institutional affiliations.

Open Access This article is licensed under a Creative Commons Attribution 4.0 International License, which permits use, sharing, adaptation, distribution and reproduction in any medium or format, as long as you give appropriate credit to the original author(s) and the source, provide a link to the Creative Commons license, and indicate if changes were made. The images or other third party material in this article are included in the article's Creative Commons license, unless indicated otherwise in a credit line to the material. If material is not included in the article's Creative Commons license and your intended use is not permitted by statutory regulation or exceeds the permitted use, you will need to obtain permission directly from the copyright holder. To view a copy of this license, visit http://creativecommons.org/licenses/by/4.0/.

(C) The Author(s) 2020 